\title{
Performance of a Nonlinear Real-Time Optimal Control System for HEVs/PHEVs during Car Following
}

\author{
Kaijiang Yu and Junqi Yang \\ School of Electrical Engineering and Automation, Henan Polytechnic University, Jiaozuo 454000, China \\ Correspondence should be addressed to Kaijiang Yu; yu.kaijiang@163.com
}

Received 20 March 2014; Accepted 23 May 2014; Published 19 June 2014

Academic Editor: Yuxin Zhao

Copyright (C) 2014 K. Yu and J. Yang. This is an open access article distributed under the Creative Commons Attribution License, which permits unrestricted use, distribution, and reproduction in any medium, provided the original work is properly cited.

\begin{abstract}
This paper presents a real-time optimal control approach for the energy management problem of hybrid electric vehicles (HEVs) and plug-in hybrid electric vehicles (PHEVs) with slope information during car following. The new features of this study are as follows. First, the proposed method can optimize the engine operating points and the driving profile simultaneously. Second, the proposed method gives the freedom of vehicle spacing between the preceding vehicle and the host vehicle. Third, using the HEV/PHEV property, the desired battery state of charge is designed according to the road slopes for better recuperation of free braking energy. Fourth, all of the vehicle operating modes engine charge, electric vehicle, motor assist and electric continuously variable transmission, and regenerative braking, can be realized using the proposed real-time optimal control approach. Computer simulation results are shown among the nonlinear real-time optimal control approach and the ADVISOR rule-based approach. The conclusion is that the nonlinear real-time optimal control approach is effective for the energy management problem of the HEV/PHEV system during car following.
\end{abstract}

\section{Introduction}

In recent years, hybrid electric vehicles (HEVs) and plugin hybrid electric vehicles (PHEVs) have become a research hotspot due to the rising price of fossil fuels and environmental problems. HEVs and PHEVs (referred as XEVs) use a battery to add an extra degree of freedom to the power sources. It can downsize the internal combustion engine, optimize the engine operating point, use the battery electricity, and regenerate dissipation kinematic energy during deceleration, which help to improve fuel economy and reduce emissions $[1,2]$.

A lot of works have been published on the energy management problem of HEV systems. These approaches are typical in a family of optimal control techniques. They can be subdivided into four categories: numerical optimization, analytical optimal control theories, instantaneous optimization, and heuristic control techniques [3]. The most representative of numerical optimization is dynamic programming (DP) $[3,4]$. However DP is based on fixed speed patterns which are impossible to get in reality. A kind of analytical optimal control techniques is Pontryagin's minimum principle [5].
It gives necessary conditions that the optimal solution must satisfy. It also needs to know the entire driving cycle in advance. The instantaneous optimization includes the equivalent consumption minimization strategy (ECMS) $[3,6]$. It is based on instantaneous optimization and is easy to implement in real-time. However, it cannot guarantee the optimality over the whole driving cycle. Heuristic control techniques like rule-based control strategies are robust, but they are impossible to guarantee the optimality. In [7], dynamic programming, quadratic programming, and model predictive control (MPC) solutions of HEV energy management problems were presented. A model predictive control approach was used to investigate the energy management problem of a power-split HEV over standard driving cycles in [8]. A new charge/discharge control system for hybrid electric vehicles based on the use of car navigation information was proposed in [9].

The literature related to PHEV energy management problems provides a lot of approaches using the ideas of modelling and controlling the powertrain components for better fuel economy. A stochastic optimal control approach for power management in plug-in hybrid electric vehicles was 
proposed by [2]. Energy-optimal control of plug-in hybrid electric vehicles for real-world driving cycles was proposed by [10]. The Gipps car following model was applied to the local road trip modeling of plug-in hybrid electric vehicle power management using historical traffic data on flat roads in [11]. The authors of [12] proposed a new approach to optimal power management of plug-in hybrid electric vehicles in the charge-depletion mode with driving cycle modeling based on the historic traffic information. Both the dynamic programming and the equivalent consumption minimization strategy (see [13-15]) were utilized to optimize the battery state of charge (SOC) profile with terrain, vehicle speed, and trip distance information for a PHEV power management problem in [16].

Although model predictive control is also in the numerical optimization class, its advantage is its predictive nature. The method can use road traffic information in the near future [9] and be applicable to the unfixed speed pattern [17]. Based on a simple and accurate model of the system, MPC can provide real-time control for the system. This paper examines energy management problems of both HEVs and PHEVs. The fuel economy optimization results of XEVs rely strongly on the future road load. The battery SOC can be scheduled optimally using the future road load.

When the slope information in advance is predicted, the battery can be depleted slowly in the PHEV case or be charged up in the HEV case, before the upslope. So the $\mathrm{XEV}$ can make best use of the battery charged power to assist the vehicle driving. Then the battery SOC is reduced to be prepared for the upcoming downhill battery charging. At last the battery is charged up by the free regenerative braking energy. These make better use of the high efficiency points of the engine and the regenerative braking energy. The preceding vehicle is assumed to be equipped with an ecological driver-assistance system developed by the authors of [17] and is controlled by an HEV energy management nonlinear model predictive controller proposed by the authors of $[18,19]$. Since ordinary drivers have some intelligence, it is more reasonable to assume an eco-driving preceding vehicle (PV) than a conventional proportional-integral controlled preceding vehicle. For example, a driver will accelerate the vehicle before the up slope and decelerate the vehicle before the down slope to make good use of the vehicle inertia kinetic energy. This intelligent driver behavior was realized by [18]. When this preceding vehicle eco-driving behavior is predicted, the following vehicle can schedule the speed and the vehicle spacing optimally using a nonlinear real-time optimal control approach. Especially for MPC, the future road load can be incorporated in the predictive model to better optimize the future speed profile and energy use. In other words, a decentralized nonlinear real-time optimal control system can be developed to model more real vehicle driving situations to get better fuel economy.

Recently, the vehicle GPS-based navigation technology, digital map databases, and laser sensors have been developed quickly. Prediction of future vehicle road loads like road slopes and preceding vehicle position and speed is becoming realistic, which was impossible in three decades ago. Research on look-ahead control using the GPS road slope information for the fuel optimization of a conventional powertrain heavy truck was accomplished in [20]. Both the dynamic programming and the equivalent consumption minimization strategy were utilized to optimize the battery state of charge profile with terrain information for an $\mathrm{HEV}$ power management problem in [6]. For adaptive cruise control (ACC), the emphasis is on safely increasing driving comfort rather than increasing road capacity. Therefore, normally a constant headway or other safe following policies are used to determine the following distance [21]. In [22], two different longitudinal control policies for automatically controlled vehicles were investigated. One was based on maintaining a constant spacing between the vehicles while the other was based upon maintaining a constant headway (or time) between successive vehicles.

In our work $[18,19]$, a nonlinear model predictive control algorithm using a simplified model for a power-split HEV was proposed to optimize the fuel economy. We assumed that the engine always worked along its optimal operating line which was an industrial traditional energy management strategy for commercially available HEVs in [23]. In this paper, we release the above general rule to search whole areas of the engine fuel consumption map for better fuel economy. This work differs from our previous work in that it presents a real-time implementable algorithm using slope and traffic information under a model predictive control structure.

The rest of this paper is organized as follows. In Section 2, the nonlinear plant model is derived. Section 3 formulates the nonlinear real-time optimal control algorithm. Section 4 presents comparative simulation results among the nonlinear real-time optimal control approach, the dynamic programming approach, the Pontryagin's minimum principle approach, and the ADVISOR [24] rule-based approach (see [25]). Section 5 provides conclusions.

\section{Nonlinear Plant Model}

The configuration of the power-split HEV/PHEV system is shown in Figure 1. The power-split device is the key component of the power-split HEV/PHEV system and has both functionality of a speed coupler and CVT. There are five dynamic components: the engine, the battery, two motor/generators (M/Gs), and the wheels in this power-split $\mathrm{HEV} / \mathrm{PHEV}$ system. The power-split device property which reveals the torque and speed relationships among the engine, $\mathrm{M} / \mathrm{Gs}$, and the road load can be expressed as follows $[4,26]$ :

$$
\begin{gathered}
I_{\mathrm{M} / \mathrm{G} 1} \dot{\omega}_{\mathrm{M} / \mathrm{G} 1}=\tau_{\mathrm{M} / \mathrm{G} 1}+f S \\
\left(I_{\mathrm{M} / \mathrm{G} 2}+\frac{I_{w}}{g_{f}^{2}}+m \frac{r_{w}^{2}}{g_{f}^{2}}\right) \dot{\omega}_{\mathrm{M} / \mathrm{G} 2} \\
=\tau_{\mathrm{M} / \mathrm{G} 2}-\frac{\tau_{\text {resist }}+\tau_{\text {brake }}}{g_{f}}+f R, \\
I_{\text {eng }} \dot{\omega}_{\text {eng }}=\tau_{\text {eng }}-f(R+S), \\
\tau_{\text {resist }}=r_{w} m g(\mu \cos (\theta)+\sin (\theta))+\frac{1}{2} \rho C_{D} A r_{w} v^{2}
\end{gathered}
$$




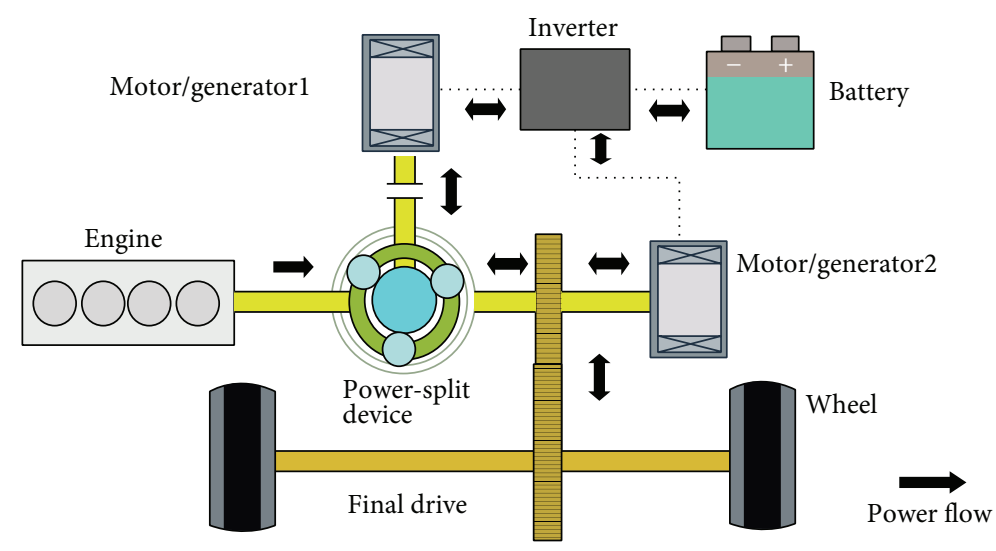

Figure 1: Model of the HEV/PHEV. Diagram adapted from [4].

where $S$ and $R$ are the number of the sun gear and the ring gear teeth, respectively; $\tau_{\mathrm{M} / \mathrm{G} 1}, \tau_{\mathrm{M} / \mathrm{G} 2}, \tau_{\text {resist }}, \tau_{\text {brake }}$, and $\tau_{\text {eng }}$ are the torque of $M / G 1, M / G 2$, the vehicle resistance, the friction brake, and the engine, respectively; $\omega_{\mathrm{M} / \mathrm{G} 1}, \omega_{\mathrm{M} / \mathrm{G} 2}$, and $\omega_{\text {eng }}$ are the angular velocities of M/G1, M/G2, and the engine, respectively; $g_{f}$ is the final drive gear ratio; $v$ is the vehicle speed; $I_{\mathrm{M} / \mathrm{G} 1}, I_{\mathrm{M} / \mathrm{G} 2}, I_{w}$, and $I_{\text {eng }}$ are the inertia of $\mathrm{M} / \mathrm{G} 1, \mathrm{M} / \mathrm{G} 2$, the wheels, and the engine, respectively; $r_{w}$ is the wheel radius; $f$ is the internal force of the power-split device on the pinion gears; $\rho, C_{D}, A, m, g, \mu$, and $\theta$ are the air density, the air drag coefficient, the frontal area of the vehicle, the vehicle mass, the gravity acceleration, the rolling resistance coefficient, and the road grade, respectively.

The slope information at location $p$ is approximated by the sigmoid functions piecewise linearly as follows:

$$
\theta(p)=\frac{s_{10}}{1+e^{\left(s_{30}\left(p-s_{20}\right)\right)}}+\frac{s_{11}}{1+e^{\left(s_{31}\left(p-s_{21}\right)\right)}}+\cdots,
$$

where $s_{10}$ and $s_{11}$ decide the gradient angle. Parameters $s_{20}$ and $s_{21}$ decide the position when the gradient angle is changed. Parameters $s_{30}$ and $s_{31}$ are slope shaped parameters.

The relationships among the speed of the powertrain components are given as

$$
\begin{gathered}
S \omega_{\mathrm{M} / \mathrm{G} 1}+R \omega_{\mathrm{M} / \mathrm{G} 2}-(S+R) \omega_{\mathrm{eng}}=0, \\
\omega_{\mathrm{M} / \mathrm{G} 2}=\frac{g_{f}}{r_{w}} v .
\end{gathered}
$$

The power-balancing constraint needs to be considered. Since the power is a multiplication of the torque and the speed, the torque balance is presented in (1); the powerbalancing constraint is addressed identically. The powerbalancing can be implicitly considered.
Using (1) and (4) and eliminating the interaction force $f$, we can obtain the dynamics of the engine and M/G2:

$$
\begin{aligned}
& {\left[\begin{array}{cc}
I_{\text {eng }}+\left(\frac{S+R}{S}\right)^{2} I_{\mathrm{M} / \mathrm{G} 1} & -\frac{R(S+R)}{S^{2}} I_{\mathrm{M} / \mathrm{G} 1} \\
-\frac{R(S+R)}{S^{2}} I_{\mathrm{M} / \mathrm{G} 1} & I_{\mathrm{M} / \mathrm{G} 2}+\frac{I_{w}}{g_{f}^{2}}+\left(\frac{R}{S}\right)^{2} I_{\mathrm{M} / \mathrm{G} 1}+m \frac{r_{w}^{2}}{g_{f}^{2}}
\end{array}\right]} \\
& \times\left[\begin{array}{c}
\dot{\omega}_{\text {eng }} \\
\dot{\omega}_{\mathrm{M} / \mathrm{G} 2}
\end{array}\right]=\left[\begin{array}{c}
\tau_{\text {eng }}+\frac{S+R}{S} \tau_{\mathrm{M} / \mathrm{G} 1} \\
\tau_{\mathrm{M} / \mathrm{G} 2}-\frac{R}{S} \tau_{\mathrm{M} / \mathrm{G} 1}-\frac{\tau_{\text {resist }}+\tau_{\text {brake }}}{g_{f}}
\end{array}\right] .
\end{aligned}
$$

We evaluate the fuel consumption rate using the Willan's line method [27]. It uses the function of the engine speed and torque to approximate the engine fuel consumption rate map directly, which leads to more accurate results than those of polynomial approximations. The fuel consumption rate can be expressed as follows [28]:

$$
\dot{m}_{f}=\frac{a \tau_{\mathrm{eng}} \omega_{\mathrm{eng}}+b \omega_{\mathrm{eng}}+c \omega_{\mathrm{eng}}^{3}}{h+k \omega_{\mathrm{eng}}+l \omega_{\mathrm{eng}}^{2}},
$$

where $\dot{m}_{f}$ is the fuel consumption rate; $a, b, c, h, k$, and $l$ are constant parameters.

Based on the previous analysis, the system dynamics is reduced to the battery dynamics, the engine dynamics, and the vehicle dynamics. The nonlinear system model is then represented by

$$
\begin{gathered}
\dot{x}=f(x, u), \\
x=\left[\begin{array}{llll}
\omega_{\text {eng }} & p & \omega_{\mathrm{M} / \mathrm{G} 2} & x_{\mathrm{SOC}}
\end{array}\right]^{T}, \\
u=\left[\begin{array}{llll}
\tau_{\text {eng }} & \tau_{\mathrm{M} / \mathrm{G} 2} & \tau_{\mathrm{M} / \mathrm{G} 1} & \tau_{\text {brake }}
\end{array}\right]^{T},
\end{gathered}
$$




$$
\begin{aligned}
& f(x, u)=\left[\begin{array}{c}
M \tau_{\text {eng }}+N \tau_{\mathrm{M} / \mathrm{G} 2}+\left(M \frac{S+R}{S}-N \frac{R}{S}\right) \tau_{\mathrm{M} / \mathrm{G} 1}-N \frac{\tau_{\text {resist }}+\tau_{\text {brake }}}{g_{f}} \\
\frac{r_{w}}{g_{f}} \omega_{\mathrm{M} / \mathrm{G} 2} \\
N \tau_{\text {eng }}+P \tau_{\mathrm{M} / \mathrm{G} 2}+\left(N \frac{S+R}{S}-P \frac{R}{S}\right) \tau_{\mathrm{M} / \mathrm{G} 1}-P \frac{\tau_{\text {resist }}+\tau_{\text {brake }}}{g_{f}} \\
-\frac{V_{\mathrm{OC}}-\sqrt{V_{\mathrm{OC}}^{2}-4 P_{\text {batt }} R_{\text {batt }}}}{2 R_{\text {batt }} \mathrm{Q}_{\text {batt }}}
\end{array}\right], \\
& {\left[\begin{array}{cc}
M & N \\
N & P
\end{array}\right]=\left[\begin{array}{cc}
I_{\text {eng }}+\left(\frac{S+R}{S}\right)^{2} I_{\mathrm{M} / \mathrm{G} 1} & -\frac{R(S+R)}{S^{2}} I_{\mathrm{M} / \mathrm{G} 1} \\
-\frac{R(S+R)}{S^{2}} I_{\mathrm{M} / \mathrm{G} 1} & I_{\mathrm{M} / \mathrm{G} 2}+\frac{I_{w}}{g_{f}^{2}}+\left(\frac{R}{S}\right)^{2} I_{\mathrm{M} / \mathrm{G} 1}+m \frac{r_{w}^{2}}{g_{f}^{2}}
\end{array}\right]^{-1},}
\end{aligned}
$$

where $p$ is the vehicle position; $x_{\mathrm{SOC}}$ is the battery SOC; $V_{\mathrm{OC}}$, $R_{\text {batt }}$, and $Q_{\text {batt }}$ are the battery open circuit voltage, the battery internal resistance, and the battery capacity, respectively; and $M, N$, and $P \in \mathbb{R}$. We use the vehicle position and the vehicle speed to represent the vehicle dynamics. The battery power $P_{\text {batt }}$ is governed by

$$
P_{\text {batt }}=\tau_{\mathrm{M} / \mathrm{G} 1} \omega_{\mathrm{M} / \mathrm{G} 1}+\tau_{\mathrm{M} / \mathrm{G} 2} \omega_{\mathrm{M} / \mathrm{G} 2} .
$$

The motor/generator energy loss is ignored due to the two motor/generators high efficiency.

Since an approximate continuous and differentiable mathematical engine model is needed for the model predictive control algorithm, the nonlinear engine fuel model is used as above. However, as for the fuel economy evaluation in the ultimate simulation, the high fidelity engine model which is a lookup table that provides the engine fuel rate and efficiency as a function of instantaneous engine speed and engine torque is used. The configuration of the HEV/PHEV in this work can stop idling of the engine using the electric CVT. The efficiency of other components of the HEV/PHEV system like the CVT and the power electronics is assumed to be 1 due to their high efficiency. The approximate models of the engine and the battery for optimal control are used to integrate with the high fidelity engine map model in the simulation.

The nonlinear model of the power-split HEV/PHEV with slope information includes the vehicle speed dynamics. The vehicle speed profile can be optimized with this nonlinear model.

\section{Nonlinear Real-Time Optimal Control}

The optimal control problem is defined as

$$
\begin{array}{ll}
\min _{u} & J=\int_{t}^{t+T} L(x(\tau \mid t), u(\tau \mid t)) d \tau \\
\text { subject to } & \tau_{\mathrm{M} / \mathrm{G} 2 \min } \leq \tau_{\mathrm{M} / \mathrm{G} 2}(\tau \mid t) \leq \tau_{\mathrm{M} / \mathrm{G} 2 \max } \\
& \tau_{\mathrm{M} / \mathrm{G} 1 \min } \leq \tau_{\mathrm{M} / \mathrm{G} 1}(\tau \mid t) \leq \tau_{\mathrm{M} / \mathrm{G} 1 \max } \\
& 0 \leq \tau_{\text {brake }}(\tau \mid t) \leq \tau_{\text {brakemax }},
\end{array}
$$

where $T$ is the prediction horizon; $\tau_{\mathrm{M} / \mathrm{G} 2 \max }, \tau_{\mathrm{M} / \mathrm{G} 2 \mathrm{~min}}$, $\tau_{\mathrm{M} / \mathrm{G} 1 \mathrm{max}}, \tau_{\mathrm{M} / \mathrm{G} 1 \mathrm{~min}}$, and $\tau_{\text {brakemax }}$ denote the bounds of the control inputs.
The following objectives are considered in this optimal control problem.

$L_{x}$ : the fuel consumption is minimized.

$L_{y}:$ the vehicle deceleration or acceleration is moderated.

$L_{z}$ : the vehicle speed is kept near to its desired value.

$L_{d}$ : the battery SOC is kept near to its desired value. This is one of the cores of the proposed approach. We adapt the battery energy to the vehicle future energy requirements by setting the desired battery SOC as a function of road slopes which represent the main part of the future road load.

$L_{e}$ : the battery SOC constraint is kept satisfied.

$L_{f}$ : the engine speed constraint is kept satisfied.

$L_{g}:$ the M/G2 speed constraint is kept satisfied.

$L_{h}$ : the mechanical brake use is minimized.

$L_{i}:$ the M/G1 speed constraint is kept satisfied.

$L_{j}$ : the battery power constraint is kept satisfied.

$L_{k}$ : the engine torque constraint is kept satisfied.

$L_{l}$ : the following distance constraint is kept satisfied. This is also one of the cores of the proposed approach. The following distance constraint is kept in a predictive controller structure. The host vehicle maneuvers are independent of the preceding vehicle. The proposed approach does not require intervehicle communication. The following distance is varied above the minimum following distance, which improves the freedom of eco-driving car following control to optimize the driving profile for better fuel economy.

$L_{m}$ : the battery power use is moderated.

The cost function $L$ is defined as follows:

$$
\begin{gathered}
L=w_{x} L_{x}+w_{y} L_{y}+w_{z} L_{z}+w_{d} L_{d}+w_{e} L_{e}+w_{f} L_{f} \\
+w_{g} L_{g}+w_{h} L_{h}+w_{i} L_{i}+w_{j} L_{j}+w_{k} L_{k} \\
+w_{l} L_{l}+w_{m} L_{m}, \\
L_{x}=\dot{m}_{f}, \\
L_{y}=\frac{1}{2}\left(\frac{r_{w}}{g_{f}} \dot{\omega}_{\mathrm{M} / \mathrm{G} 2}+g \sin (\theta)\right)^{2},
\end{gathered}
$$




$$
\begin{gathered}
L_{z}=\frac{1}{2}\left(v-v_{d}\right)^{2}, \\
L_{e}=-\ln \left(x_{\mathrm{SOC}}-\mathrm{SOC}_{\min }\right)-\ln \left(\mathrm{SOC}_{\max }-x_{\mathrm{SOC}}\right), \\
L_{f}=-\ln \left(\omega_{\text {eng }}\right)-\ln \left(\omega_{\text {eng max }}-\omega_{\mathrm{eng}}\right), \\
L_{g}=-\ln \left(\omega_{\mathrm{M} / \mathrm{G} 2}\right)-\ln \left(\omega_{\mathrm{M} / \mathrm{G} 2 \max }-\omega_{\mathrm{M} / \mathrm{G} 2}\right), \\
L_{h}=\frac{1}{2}\left(\tau_{\text {brake }}\right)^{2}, \\
L_{i}=-\ln \left(\omega_{\mathrm{M} / \mathrm{G} 1}-\omega_{\mathrm{M} / \mathrm{G} 1 \text { min }}\right)-\ln \left(\omega_{\mathrm{M} / \mathrm{G} 1 \text { max }}-\omega_{\mathrm{M} / \mathrm{G} 1}\right), \\
L_{j}=-\ln \left(P_{\text {batt }}-P_{\text {batt min }}\right)-\ln \left(P_{\text {batt max }}-P_{\text {batt }}\right), \\
L_{k}=-\ln \left(\tau_{\text {eng }}\right)-\ln \left(\tau_{\text {eng max }}-\tau_{\text {eng }}\right), \\
L_{m}=P_{\text {batt. }} .
\end{gathered}
$$

The parameter $v_{d}$ is the desired vehicle speed. Fuel economy is affected by the steady cruise speed. The best fuel economy occurs at a steady speed around $60 \mathrm{~km} / \mathrm{h}$. This speed is chosen as the desired vehicle speed. The parameters $w_{x}, w_{y}$, $w_{z}, w_{d}, w_{e}, w_{f}, w_{g}, w_{h}, w_{i}, w_{j}, w_{k}$, and $w_{l}$ are the weights. The parameters $\mathrm{SOC}_{\min }, \mathrm{SOC}_{\text {max }}, \omega_{\text {eng max }}, \omega_{\mathrm{M} / \mathrm{G} 2 \max }, \omega_{\mathrm{M} / \mathrm{G} 1 \min }$, $\omega_{\mathrm{M} / \mathrm{G} 1 \text { max }}, P_{\text {batt min }}, P_{\text {batt max }}$, and $\tau_{\text {eng max }}$ denote the bounds of the parameters. The parameter $\tau_{\text {eng max }}$ is a state variant control input. It is a function of the engine speed.

The last term concerning the battery power use is inspired by the equivalent consumption minimization strategy. The equivalent consumption minimization strategy assumes that the current battery energy use will cost the same amount of fuel energy in the future as it does in the current driving conditions [1]. So this term can control the speed of battery charge depleting. term:

The battery energy is made better use of by the following

$$
L_{d}=\frac{1}{2}\left(x_{\mathrm{SOC}}-\operatorname{SOC}_{d}(p)\right)^{2},
$$

where $\operatorname{SOC}_{d}(p)$ is the desired battery SOC value. It is designed using the road slope information beforehand to make better use of the battery energy.

The vehicle spacing optimization term is as follows:

$$
L_{l}=-\ln \left(p_{p}(t)+v_{p}(t)(\tau-t)-p(t)-l_{p}-d_{\min }\right),
$$

where the parameters $p_{p}, v_{p}, l_{p}$, and $d_{\min }$ denote the preceding vehicle position, the preceding vehicle speed, the preceding vehicle length, and the minimum vehicle spacing. The preceding vehicle speed in the prediction horizon is assumed to be constant, and its value is the same as the observed preceding vehicle speed at the beginning of the nonlinear real-time optimal control algorithm. In this way, the vehicle spacing can be kept above the minimum vehicle spacing in the prediction horizon.

Both the engine operating point and the driving profile can be optimized using the above performance index. The optimal driving profile can be decided in real-time, which is different from the predetermined profile in other papers.

In [29-31], the authors stated that the conventional engine OOL idea is valid only if the power transmission loss is negligible or if it shows only a mild change throughout the operation condition. However, HEVs have far more complicated and irregular power transmission mechanisms and characteristics than conventional vehicles do. This complexity is mainly due to the electrical power transmission paths which involve nonlinear power conversion losses in $\mathrm{M} / \mathrm{Gs}$. In other words, HEVs have an energy buffer like batteries whose efficiency is highly nonlinear to the input road loads. The battery can utilize the free regenerative braking energy to improve fuel economy significantly. The engine optimal operation for HEVs corresponding to the system optimality needs to be reconsidered. For real-time implementation, the fuel model needs to be continuous and differentiable. The fuel model needs simplifications and also to be accurate enough. It is different from the engine map model which cannot be predictable and implemented in realtime. As for the physical constraint, it is guaranteed by the second term of (10). The discontinuous jump of the engine speed will cause the discontinuous fly of the vehicle speed because of the planetary set. This will lead a very large punitive value of the vehicle acceleration which is included in the second term of (9).

The log barrier functions are introduced as penalizing terms for violations of the state constraints and the state variant control input constraint. The value of the performance index becomes very large when the constraints are being violated. By doing so, the state constraints and the state variant control input constraint of the system are satisfied. The general rule that the engine always works along its optimal operating line does not promise optimal fuel economy. Due to lack of future road load information, the engine may work in the low efficiency parts of the engine optimal operating line. We do not follow the industrial tradition which assumes that the engine always works along its optimal operating line in the commercially available HEV/PHEV energy management strategy. The fuel economy is optimized using the only term concerning the fuel consumption rate in the cost function. It will search the whole areas of the engine fuel consumption map for better fuel economy. In this way we want to develop the full strength of HEVs/PHEVs.

The inequality constraint in the optimal control problem is converted to an equality constraint by introducing a dummy input $u_{d}$ for computation simplicity as follows:

$$
C(x(t), u(t))=u^{2}(t)+u_{d}^{2}(t)-u_{\max }^{2}=0,
$$

where $u_{\max }$ denotes the bound of the control input.

To solve this optimal control problem with the calculus of variation method [32], the Hamiltonian function is defined by

$$
H(x, u, \lambda, \psi)=L(x, u)+\lambda^{T} f(x, u)+\psi^{T} C(x, u),
$$

where $\lambda$ denotes the costate and $\psi$ denotes the Lagrange multiplier associated with the equality constraint. 
The first-order necessary conditions for the optimal control input $u$, the multiplier $\psi$, and the costate $\lambda$ are obtained using the calculus of variation as

$$
\begin{gathered}
\dot{x}=f(x, u), \quad x\left(t_{0}\right)=x_{0}, \\
\dot{\lambda}=-\frac{\partial H}{\partial x}, \quad \lambda(t+T)=0, \\
\frac{\partial H}{\partial u}=0, \\
C(x, u)=0,
\end{gathered}
$$

where $t_{0}$ is the initial time and $x_{0}$ is the initial state.

The derivative of the costate $\lambda$ concerning the slope information and the battery SOC is obtained as

$$
\begin{aligned}
\dot{\lambda}_{2}= & -\lambda_{1} \frac{\partial \dot{\omega}_{\text {eng }}}{\partial p}-\lambda_{3} \frac{\partial \dot{\omega}_{\mathrm{M} / \mathrm{G} 2}}{\partial p}-w_{y} \frac{\partial L_{y}}{\partial p}-w_{l} \frac{\partial L_{l}}{\partial p} \\
& -w_{d} \frac{\partial L_{d}}{\partial p}, \\
\dot{\lambda}_{4}= & -w_{d}\left(x_{\mathrm{SOC}}-\mathrm{SOC}_{d}\right) \\
& -w_{e}\left(\frac{1}{\mathrm{SOC}_{\max }-x_{\mathrm{SOC}}}-\frac{1}{x_{\mathrm{SOC}}-\mathrm{SOC}_{\min }}\right) .
\end{aligned}
$$

It reveals that the costate of the vehicle position is related to the two power devices, the terms concerning the vehicle acceleration or deceleration, the desired battery SOC, and the vehicle spacing in the cost function. And the battery SOC costate is affected by the battery desired SOC and the bounds of the battery SOC. A large costate will lead to the small variation of the battery SOC. A small costate will lead to the large variation of the battery SOC. A well-tuned performance index and a set of well-tuned weights can lead to a better system.

The structure of the nonlinear model predictive control system is shown in Figure 2. The system inputs contain the control inputs. The system outputs consist of the vehicle states. The predictive controller uses terrain information from a digital map to calculate $\operatorname{SOC}_{d}(p)$ and $\theta(p)$. The energy management problem can be viewed as an optimal control problem which is addressed here using a nonlinear real-time optimal control approach.

At each time $t$, the optimal control input is computed by solving the above optimal control problem during the prediction horizon $T$. Only the first element of the optimal control sequence is applied. At the next time step, the prediction horizon moves forward and the process is repeated [33].

\section{Computer Simulations}

4.1. Comparison Controllers. There are four simulations in this work. They are the vehicle tracking nonlinear real-time optimal control (ROC) approach for the HEV, the vehicle tracking ADVISOR rule-based (TRB) approach for the HEV, the vehicle tracking nonlinear real-time optimal control

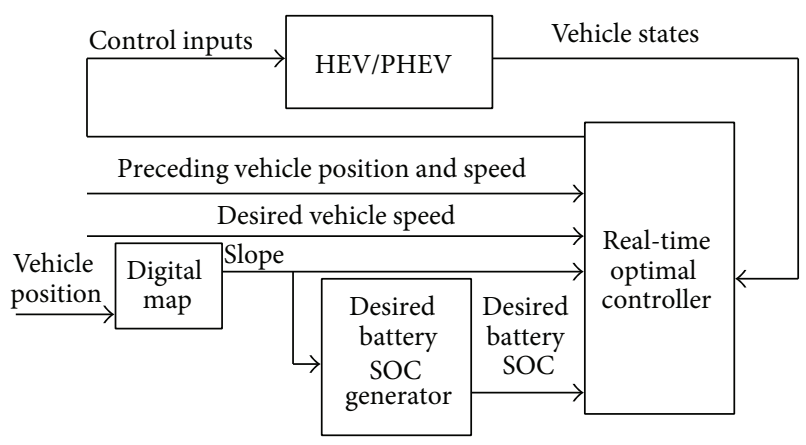

FIGURE 2: Structure of the nonlinear real-time optimal control system.

approach for the PHEV, and the vehicle tracking ADVISOR rule-based approach for the PHEV. The two vehicle tracking nonlinear real-time optimal control approaches for HEVs/PHEVs are the proposed approaches. The rule-based control for HEVs introduces a set of rules to decide the power split between the engine and the battery after the vehicle states are observed. The ADVISOR rule-based control approach is utilized as a comparison for the proposed vehicle tracking nonlinear real-time optimal control approach for the HEV. The PHEV all-electric charge depletion followed by charge sustenance control strategy used in the ADVISOR simulation software is utilized as a comparison for the proposed vehicle tracking nonlinear real-time optimal control approach for the PHEV. The driving pattern used in the vehicle tracking ADVISOR approach is obtained from an adaptive cruise control (ACC) method [22]. The control input of the tracking vehicle using the ACC method is calculated as follows [22]:

$$
\begin{aligned}
& u_{\mathrm{ACC}}(t) \\
& =\frac{v_{p}(t)-v(t)-k\left(h v(t)+d_{\text {min }}-\left(p_{p}(t)-p(t)-l_{p}\right)\right)}{h},
\end{aligned}
$$

where $k$ and $h$ are constant parameters set as $k=0.08$ and $h=0.15$ for HEVs and $k=0.08$ and $h=0.2$ for PHEVs, respectively. The preceding vehicle is controlled using the same algorithm as that in Section 3 without the vehicle spacing cost term and the battery power use term. It is a kind of eco-driving method using the ROC approach.

4.2. Test Road Slope Profiles from a Digital Map and Calculation of the Road Slope and the Desired Battery SOC. The effectiveness of the proposed energy management system of the power-split HEV is evaluated using the slope information of a real road. It is a road from the Imajuku traffic light position to the Hatae traffic light position which is $6.2[\mathrm{~km}]$ located at Route 202, Fukuoka, Japan. The maximum slope of this road is $3.65 \%$, and the minimum slope of this road is $-3.46 \%$. This real terrain is typical in Japan where there are many hilly areas.

The effectiveness of the proposed energy management system of the power-split PHEV is evaluated using the 
slope information of a real road. It is a road from the Oimatsuda Interchange to the Numazu Interchange of the Tomei Expressway which is $50.4[\mathrm{~km}]$ located in Japan. The maximum slope of this road is $5.06 \%$, and the minimum slope of this road is $-4.79 \%$.

We set the HEV desired battery SOC value according to the road elevation which represents the main part of the future road load information. It is reasonable to utilize the road elevation information since this future road load information is known already. The desired battery SOC is assumed using the function as

$$
\begin{aligned}
& \operatorname{SOC}_{d \mathrm{HEV}}(p) \\
& =k_{\mathrm{SOCHEV}}\left(\frac{s_{1}}{1+e^{\left(s_{3}\left(p-s_{2}\right)\right)}}+\frac{s_{4}}{1+e^{\left(s_{6}\left(p-s_{5}\right)\right)}}+\cdots\right) \\
& \quad+\operatorname{SOC}_{k \mathrm{HEV}},
\end{aligned}
$$

where $k_{\mathrm{SOCHEV}}$ and $\mathrm{SOC}_{k \mathrm{HEV}}$ are constant parameters set as $k_{\mathrm{SOCHEV}}=-2.5$ and $\mathrm{SOC}_{k \mathrm{HEV}}=0.71$, respectively.

We set the PHEV desired battery SOC value according to the road elevation which represents the main part of the future road load information. The future road information can be modelled into the real-time optimal control algorithm to control the battery charge depletion for better fuel economy. The desired battery SOC is assumed using the function as

$$
\begin{aligned}
& \operatorname{SOC}_{d \mathrm{PHEV}}(p) \\
& =\frac{t}{t_{\mathrm{sim}} k_{\mathrm{SOC}}} \\
& \quad+k_{\mathrm{SOCPHEV}}\left(\frac{s_{1}}{1+e^{\left(s_{3}\left(p-s_{2}\right)\right)}}+\frac{s_{4}}{1+e^{\left(s_{6}\left(p-s_{5}\right)\right)}}+\cdots\right) \\
& \quad+\operatorname{SOC}_{k \mathrm{PHEV}},
\end{aligned}
$$

where $k_{\mathrm{SOC}}, k_{\mathrm{SOCPHEV}}$, and $\mathrm{SOC}_{k \mathrm{PHEV}}$ are constant parameters set as $k_{\mathrm{SOC}}=-0.7, k_{\mathrm{SOCPHEV}}=-2$, and $\mathrm{SOC}_{k \mathrm{PHEV}}=0.9$, respectively. $t_{\text {sim }}$ is the total simulation time.

4.3. Simulation Conditions. In these simulations, HEV parameters are used from ADVISOR 2002 [24] Toyota Prius data. PHEV parameters are also used from ADVISOR 2002 [24] Toyota Prius data with a double battery capacity. The simulation parameters are shown in Table 1 . The nonlinear real-time optimal control problem is solved using the numerical computation method: the continuation and generalized minimum residual (C/GMRES) method [34]. The C/GMRES method uses forward difference approach and discretizes the HEV/PHEV plant with a sampling interval $h_{t}$ to implement the nonlinear real-time optimal control algorithm. The flowchart of the nonlinear model predictive

\begin{tabular}{|c|c|}
\hline Parameters & Values \\
\hline$m$ & 1504 \\
\hline$C_{D}$ & 0.3 \\
\hline$g$ & $9.8\left[\mathrm{~m} / \mathrm{s}^{2}\right]$ \\
\hline$V_{\text {OCHEV }}$ & $307.9[\mathrm{~V}]$ \\
\hline$V_{\text {OCPHEV }}$ & $615.8[\mathrm{~V}]$ \\
\hline$Q_{\text {batt }}$ & $6[\mathrm{Ah}]$ \\
\hline$g_{f}$ & 3.93 \\
\hline$I_{\mathrm{MG} 1}$ & $0.0226\left[\mathrm{kgm}^{2}\right]$ \\
\hline$I_{w}$ & $3.3807\left[\mathrm{kgm}^{2}\right]$ \\
\hline$b$ & 1576 \\
\hline$h$ & 1032000 \\
\hline$l$ & -2.401 \\
\hline$R$ & 78 \\
\hline$l_{p}$ & $4.31[\mathrm{~m}]$ \\
\hline$h_{t}$ & $0.1[\mathrm{~s}]$ \\
\hline $\mathrm{SOC}_{\text {minHEV }}$ & 0.6 \\
\hline $\mathrm{SOC}_{\min \mathrm{PHEV}}$ & 0.15 \\
\hline$\tau_{\mathrm{MG} 2 \max }$ & $305[\mathrm{Nm}]$ \\
\hline$\tau_{\text {MGlmax }}$ & $55[\mathrm{Nm}]$ \\
\hline$\tau_{\text {brakemax }}$ & $2655[\mathrm{Nm}]$ \\
\hline$P_{\text {battmaxHEV }}$ & $23.684[\mathrm{~kW}]$ \\
\hline$P_{\text {battminPHEV }}$ & $-47.367[\mathrm{~kW}]$ \\
\hline$\omega_{\text {engmax }}$ & $418.8790[\mathrm{rad} / \mathrm{s}]$ \\
\hline$\omega_{\text {MGImax }}$ & $575.9587[\mathrm{rad} / \mathrm{s}]$ \\
\hline$w_{y \mathrm{HEV}}$ & 9000 \\
\hline$w_{d \mathrm{HEV}}$ & 50000000 \\
\hline$w_{f \mathrm{HEV}}$ & 10000 \\
\hline$w_{h \mathrm{HEV}}$ & 1 \\
\hline$w_{j \mathrm{HEV}}$ & 0.1 \\
\hline$w_{l \mathrm{HEV}}$ & 90 \\
\hline$w_{x \mathrm{PHEV}}$ & 19000 \\
\hline$w_{z \mathrm{PHEV}}$ & 150 \\
\hline$w_{\text {ePHEV }}$ & 1 \\
\hline$w_{g \mathrm{PHEV}}$ & 50000 \\
\hline$w_{i \mathrm{PHEV}}$ & 0.1 \\
\hline$w_{k \mathrm{PHEV}}$ & 1000 \\
\hline$w_{m \mathrm{HEV}}$ & 0.00001 \\
\hline$\rho$ & $1.23\left[\mathrm{~kg} / \mathrm{m}^{3}\right]$ \\
\hline A & $1.746\left[\mathrm{~m}^{2}\right]$ \\
\hline$\mu$ & 0.695 \\
\hline$R_{\text {battHEV }}$ & $1.0[\Omega]$ \\
\hline$R_{\text {battHev }}$ & $2.0[\Omega]$ \\
\hline$r_{w}$ & $0.287[\mathrm{~m}]$ \\
\hline$I_{\text {eng }}$ & $1.746\left[\mathrm{~m}^{2}\right]$ \\
\hline$I_{\mathrm{MG} 2}$ & $0.0226\left[\mathrm{kgm}^{2}\right]$ \\
\hline$a$ & 40.88 \\
\hline c & -0.004051 \\
\hline$k$ & 365.7 \\
\hline$S$ & 30 \\
\hline$T$ & $10[\mathrm{~s}]$ \\
\hline$d_{\min }$ & $1[\mathrm{~m}]$ \\
\hline $\mathrm{SOC}_{d}$ & 0.7 \\
\hline $\mathrm{SOC}_{\operatorname{maxHEV}}$ & 0.8 \\
\hline $\mathrm{SOC}_{\operatorname{maxPHEV}}$ & 0.95 \\
\hline$\tau_{\mathrm{MG} 2 \min }$ & $-305[\mathrm{Nm}]$ \\
\hline
\end{tabular}
control algorithm implementation is shown in Figure 3. A brief description of the solution of the real-time optimal control problem using the C/GMRES method is included in the Appendix. The nonlinear real-time optimal control algorithm is realized by utilizing the C MEX S-function
TABLE 1: Simulation parameters. 
TABLE 1: Continued.

\begin{tabular}{lc}
\hline Parameters & Values \\
\hline$\tau_{\text {MGlmin }}$ & $-55[\mathrm{Nm}]$ \\
$P_{\text {battminHEV }}$ & $-23.684[\mathrm{~kW}]$ \\
$v_{d}$ & $60[\mathrm{~km} / \mathrm{h}]$ \\
$P_{\text {battmaxPHEV }}$ & $47.367[\mathrm{~kW}]$ \\
$\omega_{\text {MGlmin }}$ & $-575.9587[\mathrm{rad} / \mathrm{s}]$ \\
$w_{x \mathrm{HEV}}$ & 39000 \\
$w_{z \mathrm{HEV}}$ & 800 \\
$w_{e \mathrm{HEV}}$ & 260000 \\
$w_{g \mathrm{HEV}}$ & 50000 \\
$w_{i \mathrm{HEV}}$ & 0.1 \\
$w_{k \mathrm{HEV}}$ & 1000 \\
$w_{\text {mHEV }}$ & 0 \\
$w_{y \mathrm{PHEV}}$ & 1000 \\
$w_{d \mathrm{PHEV}}$ & 550000 \\
$w_{f \mathrm{PHEV}}$ & 10000 \\
$w_{h \mathrm{PHEV}}$ & 1 \\
$w_{\text {jPHEV }}$ & 0.1 \\
$w_{\mathrm{PPHEV}}$ & 90 \\
\hline
\end{tabular}

builder in Matlab/Simulink. Direct control input torque of the engine, the two $M / G s$, and the mechanical brake are given by the nonlinear real-time optimal controller. The fuel economy is calculated using the engine fuel consumption map which is obtained from ADVISOR 2002.

4.4. Simulation Results. Figure 4 shows the driving profile of the real-time optimal control algorithm for the HEV. The first column of Figure 4 is the road elevation. The next five columns show the vehicle control input, the optimized vehicle speed, and the vehicle spacing. Figure 5 shows the driving profile of the real-time optimal control algorithm for the PHEV. The vehicle tracking nonlinear real-time optimal control vehicle predicts the upcoming up-down hills, and avoids the abrupt acceleration or deceleration as shown in the ACC method at the link parts of different slopes. The vehicle spacing is kept above the minimum using both the real-time optimal control and the ACC. Instead of converging to a value, the vehicle tracking nonlinear real-time optimal control approach can make good use of the vehicle spacing range to get better fuel economy with the predicted preceding eco-driving vehicle information. In this way the vehicle tracking nonlinear real-time optimal control algorithm helps to improve the fuel economy.

Figure 6 shows the power-split profile of the vehicle using the vehicle tracking real-time optimal control algorithm for the HEV. The columns of Figure 6 from the top are the road elevation, the battery SOC, the speed of the engine and the two $\mathrm{M} / \mathrm{Gs}$, the torque of the engine and the two $\mathrm{M} / \mathrm{Gs}$, and the power of the engine and the two M/Gs. Figure 7 shows the power-split profile of the vehicle using the vehicle tracking ADVISOR rule-based algorithm for the HEV. Figure 8 shows the power-split profile of the vehicle using the real-time optimal control algorithm for the PHEV. Figure 9 shows the power-split profile of the vehicle using the vehicle tracking ADVISOR rule-based algorithm for the PHEV. As for the

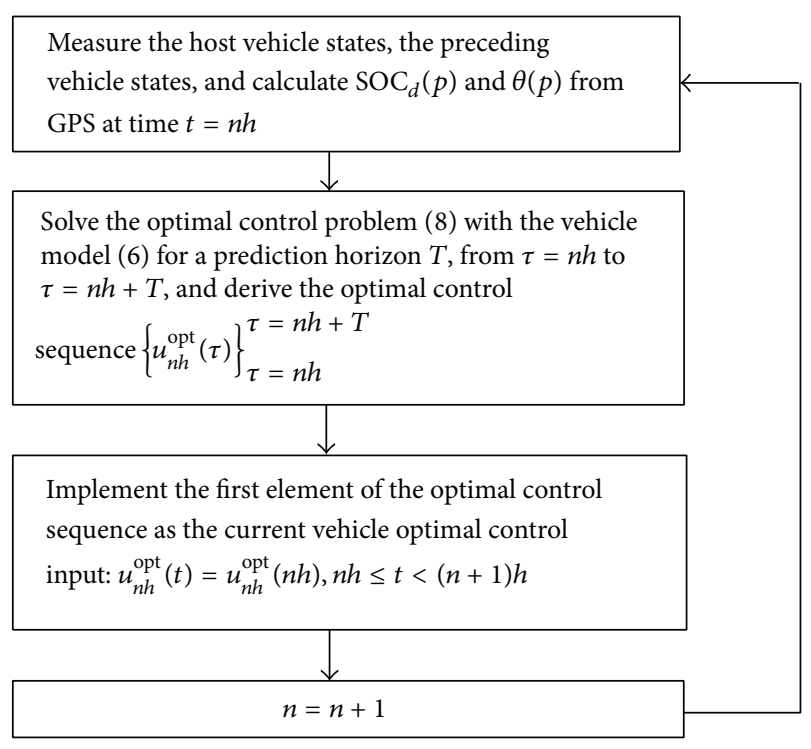

FIGURE 3: Flowchart of the nonlinear real-time optimal control algorithm.

power-split profile of the vehicle using the vehicle tracking real-time optimal control algorithm for the HEV, there is some causality between the road elevation and the battery SOC. The lowest point of the road elevation corresponds to the highest point of the battery SOC. The highest point of the road elevation corresponds to the lowest point of the battery SOC. By using the slope information in advance to better use the battery SOC range, the vehicle tracking nonlinear real-time optimal control algorithm helps to reduce the fuel consumption efficiently.

In Figure 9 the battery is depleted to its minimum allowable charge by the end of the trip. At first, the vehicle is driven by M/G2 until the battery charge is depleted to its minimum using the charge depleting mode, and then the control is switched to the charge sustaining mode. During the charge depleting mode in the above approach for the PHEV, the engine can be turned on if the driving power or torque requests exceed the capabilities of the battery or the motors. The battery SOC constraint is satisfied in the above simulations. The torque, speed, and power of the engine and M/Gs are more reasonable using the proposed real-time optimal control approach compared with the ADVISOR rule-based approach according to the commercially available Toyota Prius PHEV. There are a lot of spikes of the torque, speed, and power of the engine and M/Gs using the ADVISOR rulebased approach.

Overall, the real-time optimal control approach for the PHEV uses the M/Gs to drive the vehicle compared with the vehicle tracking real-time optimal control approach for the $\mathrm{HEV}$, which helps to improve the fuel economy. The vehicle tracking real-time optimal control approach for the HEV uses the engine fuel energy to drive the vehicle instead of the free energy recovered by the battery, which results in worse fuel economy. Since the slopes in the real road for the $\mathrm{HEV}$ are short and gentle, the fuel economy improvement is 

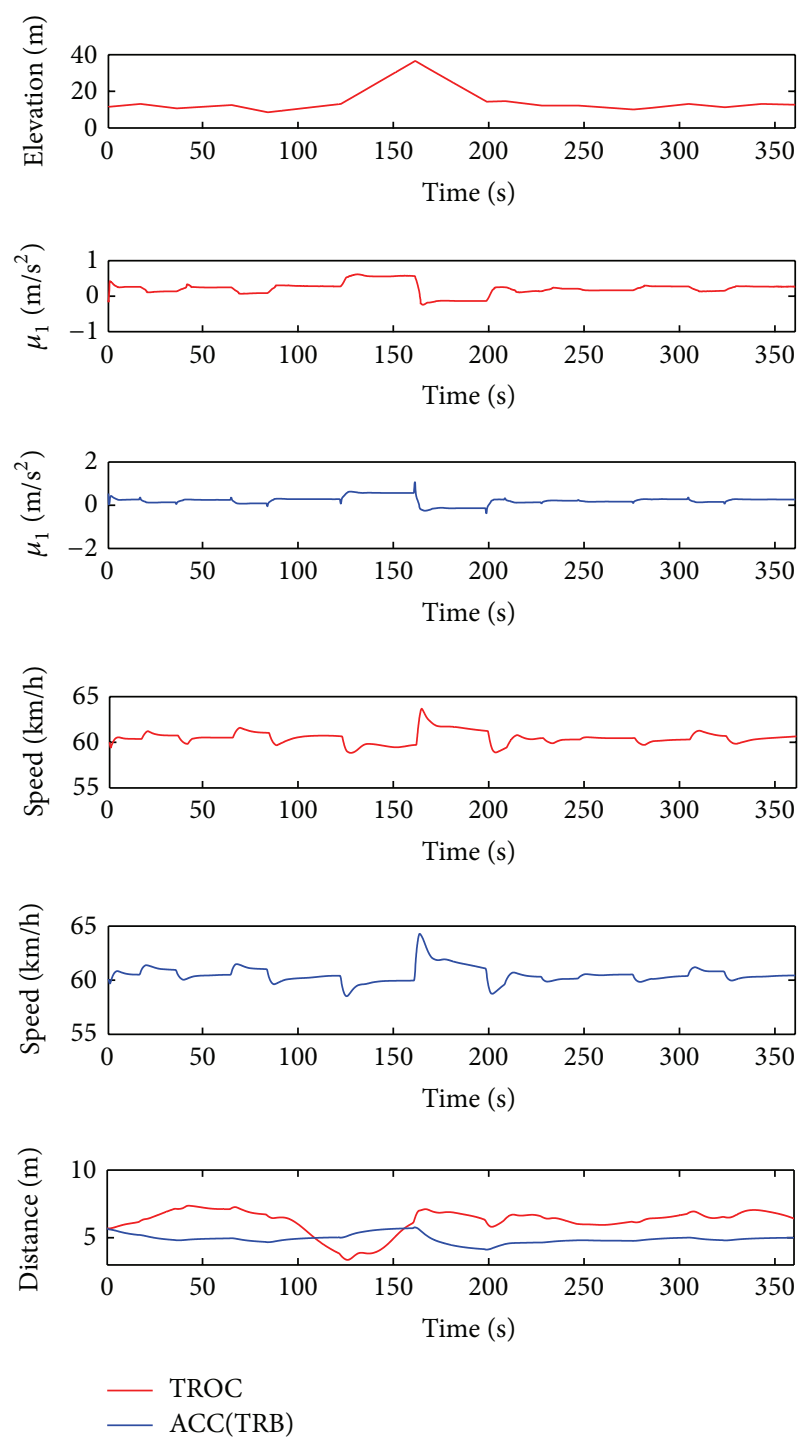

FIGURE 4: Driving profile of the vehicle tracking nonlinear real-time optimal control algorithm and the ACC algorithm for the HEV.

not significant using the vehicle tracking real-time optimal control approach algorithm for the HEV compared with that for the PHEV. Without slope previews, the engine and the $\mathrm{M} / \mathrm{Gs}$ work abruptly, especially at the beginning of the simulation; and the link parts of different slopes using the ADVISOR rule-based approach. The battery SOC decreases continually. The vehicle does not get the regenerative braking energy properly.

A significant benefit of the power-split architecture is the fact that it decouples the engine crankshaft from the road and allows the electric machines to move the engine speed where fuel efficiency is maximized [35]. This is identified by the engine operating point distribution. Figure 10 shows the distribution of the engine operating points using the vehicle tracking nonlinear real-time optimal control algorithm for the HEV. Figure 11 shows the distribution of the engine
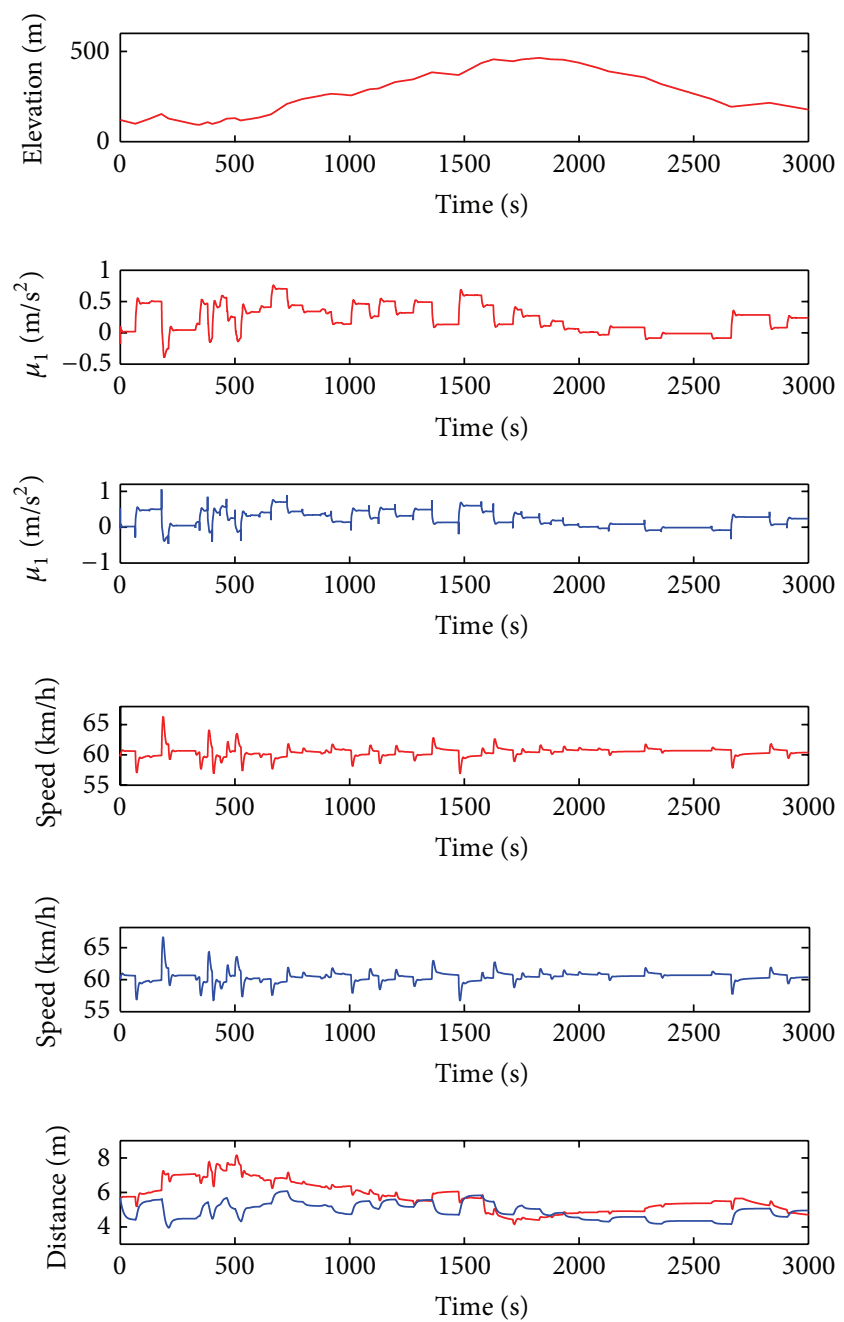

— TROC

- ACC(TRB)

FIGURE 5: Driving profile of the vehicle tracking nonlinear real-time optimal control algorithm and the ACC algorithm for the PHEV.

operating points using the vehicle tracking nonlinear realtime optimal control algorithm for the PHEV.

The line at the top left corner is the engine max torque line. The engine operating points cannot go beyond the line.

As shown in Figures 10 and 11 the vehicle tracking nonlinear real-time optimal control algorithm operates the engine at fairly low speed and high torque, which means high engine efficiency and low brake specific fuel consumption values. The vehicle tracking nonlinear real-time optimal control algorithm forces the engine to work regularly near the engine low fuel consumption rate areas. In contrast, the ADVISOR rule-based approach operates the engine at fairly high speed and low torque, which means low engine efficiency and high brake specific fuel consumption values. By adapting the battery power to the future road load, the vehicle tracking nonlinear real-time optimal control algorithm develops the ability of the power-split architecture. We can see that the 

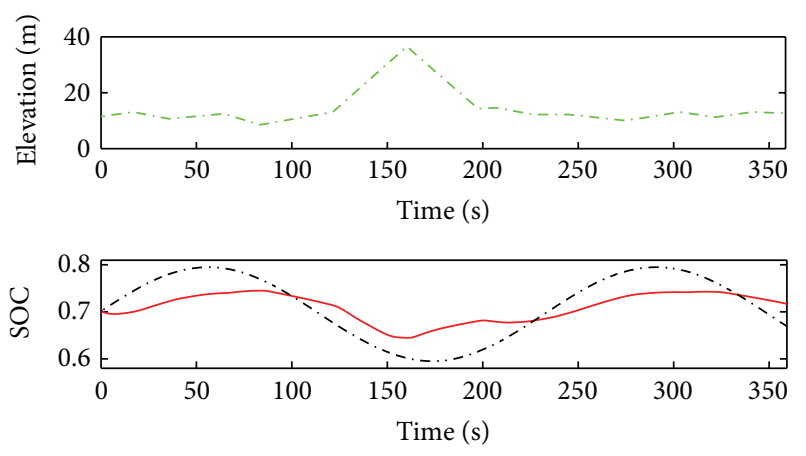

- SOC

...- $\mathrm{SOC}_{d}$

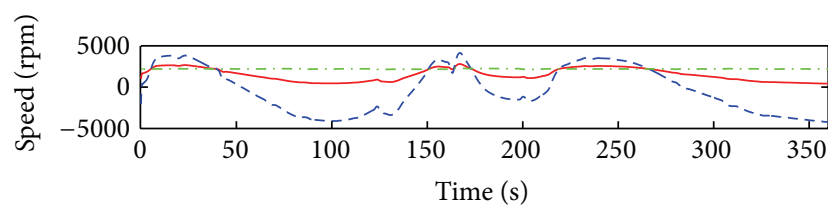

- Engine

- - - M/G

... M/G2

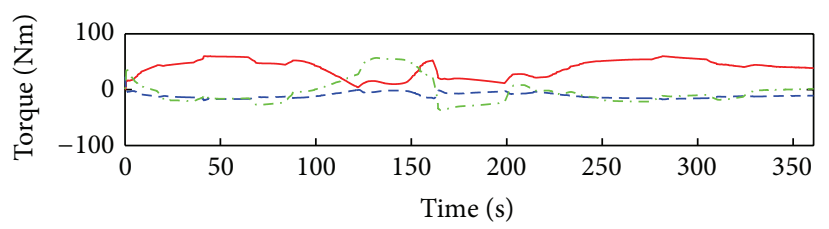

- Engine

- - - M/G1

M/G2

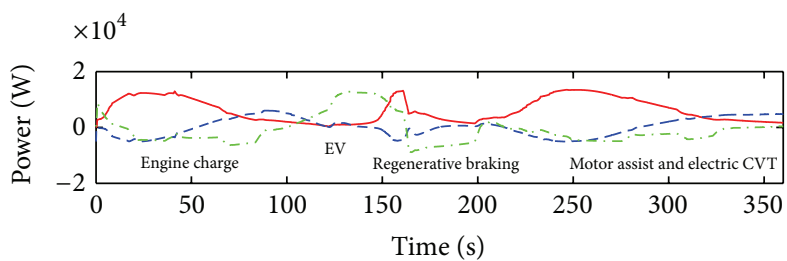

- Engine

- - - M/G1

... M/G2

FIGURE 6: Power-split profile of the vehicle using the vehicle tracking nonlinear real-time optimal control algorithm for the HEV.

engine operating points of the vehicle tracking nonlinear realtime optimal control algorithm are distributed in better areas than those of the ADVISOR algorithm. Compared with the engine operating points using the vehicle tracking nonlinear real-time optimal control algorithm for the HEV, the engine operating points using the vehicle tracking nonlinear realtime optimal control algorithm for the PHEV are distributed closer to the left corner of the engine fuel consumption map that consumes less fuel. The vehicle tracking nonlinear realtime optimal control algorithm can make the engine work in better areas rather than those along the best efficiency line
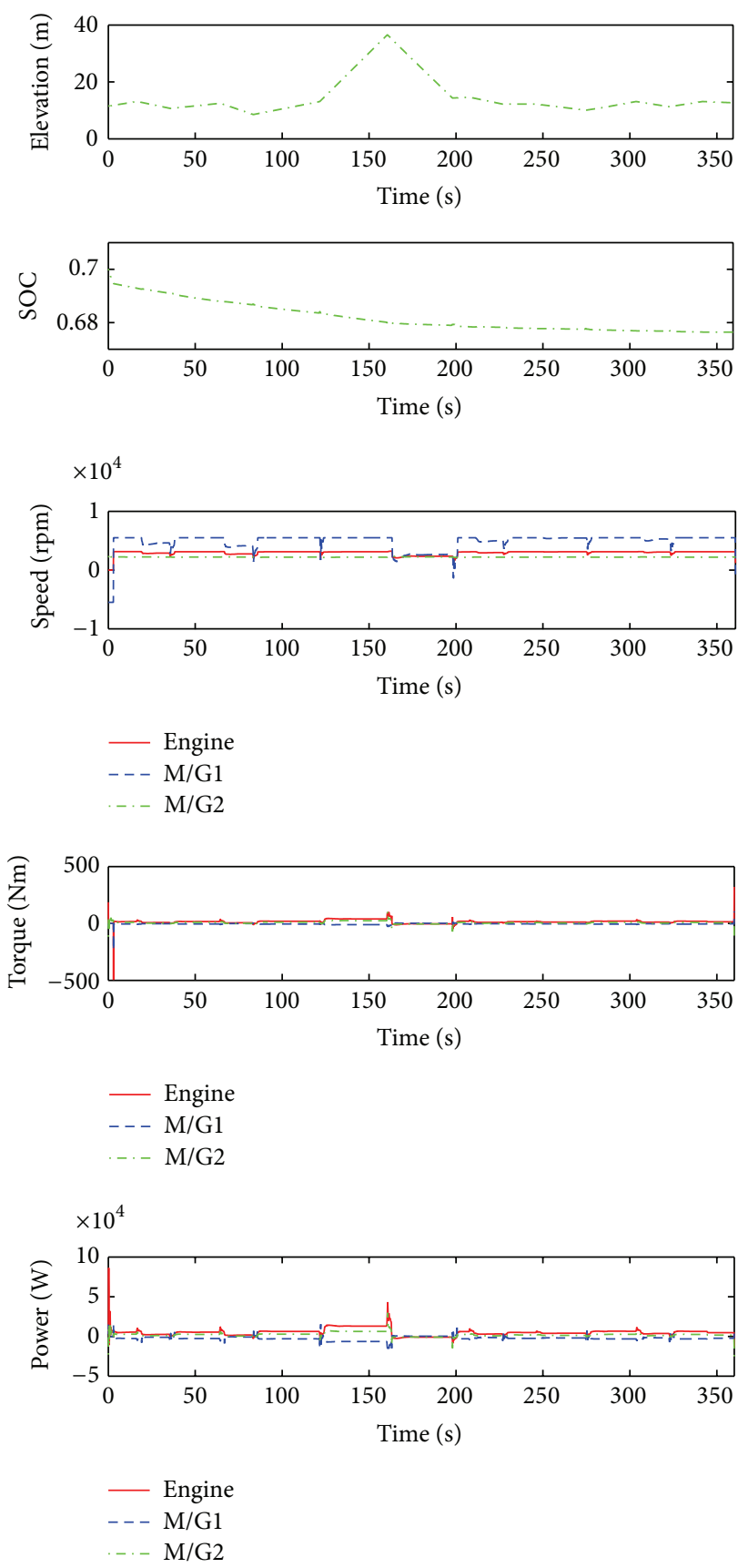

FIGURE 7: Power-split profile of the vehicle using the vehicle tracking ADVISOR rule-based algorithm for the HEV.

of the engine using the CVT. The fuel efficiency depends on the real efficiency of the engine, which makes the point that a high efficiency area is more profitable.

The overall fuel economy results are presented in Table 2. The vehicle tracking nonlinear real-time optimal control approach for the HEV can improve fuel economy by $38.6 \%$ compared to the ADVISOR rule-based approach for the HEV. The vehicle tracking nonlinear real-time optimal control approach for the PHEV can improve fuel economy by $74.6 \%$ compared to the ADVISOR rule-based approach for the 

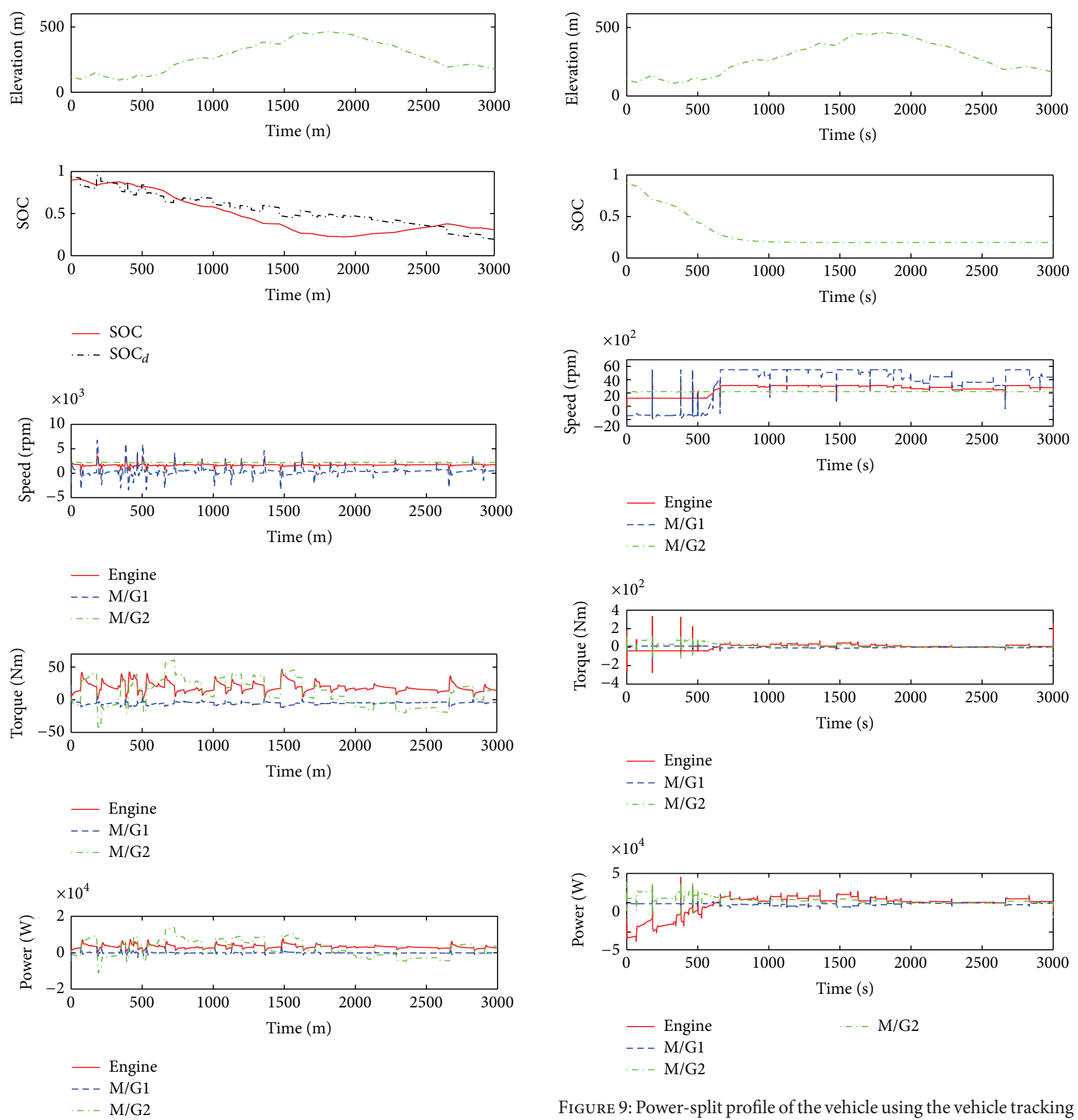

FIGURE 8: Power-split profile of the vehicle using the vehicle tracking nonlinear real-time optimal control algorithm for the PHEV.

PHEV. Since the vehicle tracking ADVISOR approach cannot avoid the acceleration or deceleration spikes at the link parts of different slopes, it gets worse fuel economy than that using the real-time optimal control approach. We can see from Figure 8 and Table 2 that better using of the battery SOC range results in better fuel economy. This leads to better fuel economy using the real-time optimal control approach for the PHEV than the real-time optimal control approach

FIGURE 9: Power-split profile of the vehicle using the vehicle tracking ADVISOR rule-based algorithm for the PHEV.

for the HEV. By using the predicted road slope information freely, the real-time optimal control algorithm can adapt the HEV/PHEV battery SOC profile according to the known bounds of the parameters to get better fuel economy. Since the fuel economy is calculated by the high fidelity map of the real engine, which is the most accurate evaluating method in the computer simulation environment, these results are promising.

The proposed vehicle tracking nonlinear real-time optimal control algorithm is fast for computation. The computer 


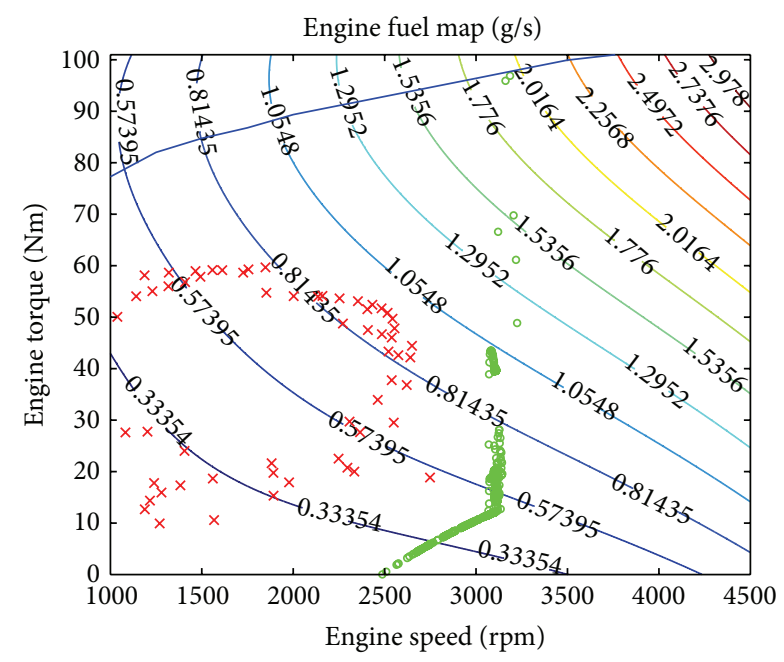

FIGURE 10: Engine operating point distribution using the vehicle tracking nonlinear real-time optimal control algorithm and the vehicle tracking ADVISOR rule-based algorithm for the HEV. The crosses and the circles denote the engine operating points of the vehicle tracking nonlinear real-time optimal control algorithm and the vehicle tracking ADVISOR rule-based algorithm, respectively.

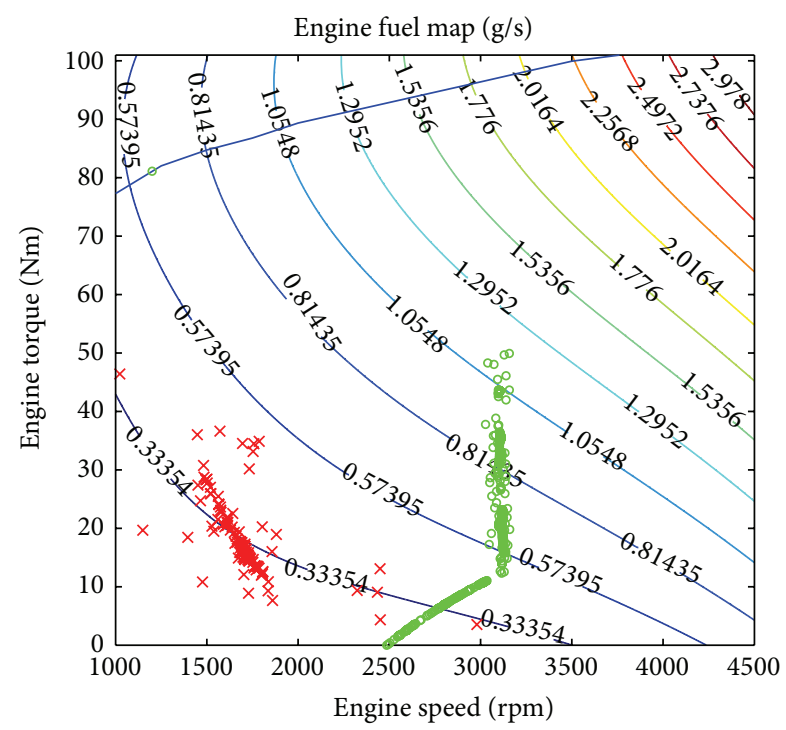

FIGURE 11: Engine operating point distribution using the vehicle tracking nonlinear real-time optimal control algorithm and the car tracking ADVISOR rule-based algorithm for the PHEV. The crosses and the circles denote the engine operating points of the vehicle tracking nonlinear real-time optimal control algorithm and the vehicle tracking ADVISOR rule-based algorithm, respectively.

simulation time for the HEV is $360[\mathrm{~s}]$, and the computer simulation time for the PHEV is 3000 [s] The computation time of the proposed vehicle tracking nonlinear real-time optimal control algorithm for the HEV is 29.0 [s]. The computation time of the proposed vehicle tracking nonlinear real-time optimal control algorithm for the PHEV is 402.7 [s]. The simulation is run in a Matlab/Simulink environment
TABLE 2: Fuel economy comparison results.

\begin{tabular}{lccc}
\hline Method & $\begin{array}{c}\text { Initial } \\
\text { SOC }\end{array}$ & $\begin{array}{c}\text { Final } \\
\text { SOC }\end{array}$ & $\begin{array}{c}\text { Fuel economy } \\
{[\mathrm{km} / \mathrm{l}]}\end{array}$ \\
\hline TROC (HEV) & 0.700 & 0.717 & $29.1(+38.6 \%)$ \\
TRB (HEV) & 0.700 & 0.677 & $21.0(+0.00 \%)$ \\
TROC (PHEV) & 0.900 & 0.307 & $45.4(+74.6 \%)$ \\
TRB (PHEV) & 0.900 & 0.188 & $26.0(+0.00 \%)$ \\
\hline
\end{tabular}

using a laptop with an Intel processor at $2.27[\mathrm{GHz}]$ processing speed and $2[\mathrm{~GB}]$ of RAM. The sampling interval is $100[\mathrm{~ms}]$. The computation time per sampling interval of the proposed vehicle tracking nonlinear real-time optimal control algorithm for the HEV is $8.1[\mathrm{~ms}]$. The computation time per sampling interval of the proposed vehicle tracking nonlinear real-time optimal control algorithm for the PHEV is 13.4 [ms]. So we can conclude that the proposed vehicle tracking nonlinear real-time optimal control algorithm has the potential for real-time vehicle control.

\section{Conclusions}

A real-time optimal control approach for the energy management problem of a power-split HEV/PHEV system during car following was presented. The nonlinear system model with road slope information was developed. The validity of the proposed algorithm was demonstrated by the significant fuel economy improvements. In the future, the traffic control signals and congestion will be modelled to get better fuel economy. A non-fragile output tracking controller [36-38] for a fleet of vehicles, which guarantees the tracking error dynamics to be robustly stable, especially to design, is our top priority.

\section{Appendix}

\section{Solution of the Real-Time Optimal Control Problem}

A brief description of the solution of the real-time optimal control problem is provided as follows.

To implement the real-time optimal control algorithm, the horizon $T$ is divided into $N$ steps, and the optimal control problem is discretized. The general discretized optimal control problem is formulated as

$$
\min _{u} \quad J=\sum_{i=0}^{N-1} L\left(x_{i}(\tau \mid t), u_{i}(\tau \mid t)\right) \Delta \tau(t)
$$

subject to

$$
\begin{aligned}
& x_{i+1}(\tau \mid t)=x_{i}(\tau \mid t)+f\left(x_{i}(\tau \mid t), u_{i}(\tau \mid t)\right) \Delta \tau(t) \\
& G\left(x_{i}(\tau \mid t), u_{i}(\tau \mid t)\right) \leq 0,
\end{aligned}
$$


where $u$ is the control input and $x$ is the state, $L$ is the cost function. $f(x, u)$ is the state equation. $G(x, u)$ is the inequality constraint.

The inequality constraint in the optimal control problem is converted to an equality constraint by introducing a dummy input $u_{d}$ for computation simplicity as follows:

$$
C(x(t), u(t))=u^{2}(t)+u_{d}^{2}(t)-u_{\max }^{2}=0,
$$

where $u_{\max }$ denotes the upper bound of the control input.

To solve this optimal control problem with the calculus of variation method [32], the Hamiltonian function is defined by

$$
H(x, u, \lambda, \psi)=L(x, u)+\lambda^{T} f(x, u)+\psi^{T} C(x, u),
$$

where $\lambda$ denotes the costate and $\psi$ denotes the Lagrange multiplier associated with the equality constraint.

The first-order necessary conditions for the optimal control input $u$, the multiplier $\psi$, and the costate $\lambda$ are obtained using the calculus of variation as

$$
\begin{gathered}
x_{i+1}(t)=x_{i}(t)+f\left(x_{i}(t), u_{i}(t)\right) \Delta \tau(t), \quad x_{0}(t)=x(t), \\
\lambda_{i}(t)=\lambda_{i+1}(t)+H_{x}\left(x_{i}(t), u_{i}(t), \lambda_{i+1}(t), \psi_{i}(t)\right) \Delta \tau(t), \\
\lambda_{N}(t)=0, \\
H_{u}\left(x_{i}(t), u_{i}(t), \lambda_{i+1}(t), \psi_{i}(t)\right)=0, \\
C(x(t), u(t))=0,
\end{gathered}
$$

where $x_{0}$ is the initial state.

To solve this optimal control problem, the continuation and GMRES (C/GMRES) method is employed for computation cost reduction. The necessary conditions of optimality for the constrained control input can be expressed as the following equation:

$$
\begin{aligned}
& F(U(\tau \mid t), x(\tau \mid t), t) \\
& :=\left[\begin{array}{c}
H_{u}\left(u_{0}(\tau \mid t), x_{0}(\tau \mid t), \lambda_{1}(\tau \mid t), \psi_{0}(\tau \mid t)\right) \\
C\left(u_{0}(\tau \mid t), x_{0}(\tau \mid t)\right) \\
\vdots \\
H_{u}\left(u_{N-1}(\tau \mid t), x_{N-1}(\tau \mid t), \lambda_{N}(\tau \mid t), \psi_{N-1}(\tau \mid t)\right) \\
C\left(u_{N-1}(\tau \mid t), x_{N-1}(\tau \mid t)\right)
\end{array}\right]=0, \\
& U(t):=\left[u_{0}^{T}(\tau \mid t), \psi_{0}^{T}(\tau \mid t), \ldots, u_{N-1}^{T}(\tau \mid t), \psi_{N-1}^{T}(\tau \mid t)\right]^{T} .
\end{aligned}
$$

$F(U(t), x(t), t)=0$ is identical to

$$
\begin{gathered}
F(U(0), x(0), 0):=0, \\
\dot{F}(U, x, t)=-A_{s} F(U(t), x(t), t),
\end{gathered}
$$

where $A_{s}$ is a stable matrix introduced to stabilize $F=0$. If $F_{U}$ is nonsingular, a differential equation for $U(t)$ can be obtained as

$$
\dot{U}=-F_{U}^{-1}\left(A_{s} F-F_{x} \dot{x}-F_{t}\right) .
$$

The above differential equation can be solved by the GMRES method. The presented approach is also a kind of continuation method. The solution curve $U(t)$ is traced by integrating the above differential equation. Because there is no need to calculate the Jacobians and the linear equation iteratively, C/GMRES method assures the real-time optimal control ability because of small computational cost. The detailed description of the solution for the real-time optimal control algorithm can be found in [34].

\section{Conflict of Interests}

The authors declare that there is no conflict of interests regarding the publication of this paper.

\section{References}

[1] A. Sciarretta and L. Guzzella, "Control of hybrid electric vehicles," IEEE Control Systems Magazine, vol. 27, no. 2, pp. 6070, 2007.

[2] S. J. Moura, H. K. Fathy, D. S. Callaway, and J. L. Stein, "A stochastic optimal control approach for power management in plug-in hybrid electric vehicles," IEEE Transactions on Control Systems Technology, vol. 19, no. 3, pp. 545-555, 2011.

[3] L. Serrao, A comparative analysis of energy management strategies for hybrid electric vehicles [Ph.D. thesis], The Ohio State University, 2009.

[4] J. Liu and H. Peng, "Modeling and control of a power-split hybrid vehicle," IEEE Transactions on Control Systems Technology, vol. 16, no. 6, pp. 1242-1251, 2008.

[5] N. Kim, S. Cha, and H. Peng, "Optimal control of hybrid electric vehicles based on Pontryagin's minimum principle," IEEE Transactions on Control Systems Technology, vol. 19, no. 5, pp. 1279-1287, 2011.

[6] C. Zhang, A. Vahidi, P. Pisu, X. Li, and K. Tennant, "Role of terrain preview in energy management of hybrid electric vehicles," IEEE Transactions on Vehicular Technology, vol. 59, no. 3, pp. 1139-1147, 2010.

[7] M. Koot, J. T. B. A. Kessels, B. de Jager, W. P. M. H. Heemels, P. P. J. van den Bosch, and M. Steinbuch, "Energy management strategies for vehicular electric power systems," IEEE Transactions on Vehicular Technology, vol. 54, no. 3, pp. 771-782, 2005.

[8] H. Borhan, A. Vahidi, A. M. Phillips, M. L. Kuang, I. V. Kolmanovsky, and S. Di Cairano, "MPC-based energy management of a power-split hybrid electric vehicle," IEEE Transactions on Control Systems Technology, vol. 20, no. 3, pp. 593-603, 2012.

[9] Y. Deguchi and T. Kawabe, "HEV charge/discharge control system based on navigation information," SAE Technical Paper 2004-21-0028, 2004.

[10] S. Stockar, V. Marano, M. Canova, G. Rizzoni, and L. Guzzella, "Energy-optimal control of plug-in hybrid electric vehicles for real-world driving cycles," IEEE Transactions on Vehicular Technology, vol. 60, no. 7, pp. 2949-2962, 2011.

[11] Q. Gong and Y. Li, “Trip based optimal power management of plug-in hybrid electric vehicle with advanced traffic modeling," SAE Technical Paper 2008-01-1316, 2008.

[12] Q. Gong, Y. Li, and Z.-R. Peng, "Trip-based optimal power management of plug-in hybrid electric vehicles," IEEE Transactions on Vehicular Technology, vol. 57, no. 6, pp. 3393-3401, 2008. 
[13] L. Guzzella and A. Sciarretta, Vehicle Propusion Systems: Introduction to Modeling and Optimization, Springer, New York, NY, USA, 2005.

[14] A. Sciarretta, M. Back, and L. Guzzella, "Optimal control of parallel hybrid electric vehicles," IEEE Transactions on Control Systems Technology, vol. 12, no. 3, pp. 352-363, 2004.

[15] G. Paganelli, S. Delprat, T. M. Guerra, J. Rimaux, and J. J. Santin, "Equivalent consumption minimization strategy for parallel hybrid powertrains," in Proceedings of the 55th Vehicular Technology Conference, pp. 2076-2081, May 2002.

[16] C. Zhang and A. Vahidi, "Route preview in energy management of plug-in hybrid vehicles," IEEE Transactions on Control Systems Technology, vol. 20, no. 2, pp. 546-553, 2012.

[17] K. Yu, M. Mukai, and T. Kawabe, "Performance of an ecodriving nonlinear MPC system for a power-split HEV during car following," SICE Journal of Control, Measurement, and System Integration, vol. 7, no. 1, pp. 55-62, 2014.

[18] K. Yu, M. Mukai, and T. Kawabe, "Model predictive control of a power-split hybrid electric vehicle system," Artificial Life and Robotics, vol. 17, no. 2, pp. 221-226, 2012.

[19] K. Yu, M. Mukai, and T. Kawabe, "A battery management system using nonlinear model predictive control for a hybrid electric vehicle," in Proceedings of the 7th IFAC Symposium on Advances in Automotive Control, September 2013.

[20] E. Hellström, M. Ivarsson, J. Åslund, and L. Nielsen, "Lookahead control for heavy trucks to minimize trip time and fuel consumption," Control Engineering Practice, vol. 17, no. 2, pp. 245-254, 2009.

[21] A. Vahidi and A. Eskandarian, "Research advances in intelligent collision avoidance and adaptive cruise control," IEEE Transactions on Intelligent Transportation Systems, vol. 4, no. 3, pp. 132153, 2003.

[22] D. Swaroop, J. K. Hedrick, C. C. Chien, and P. Ioannou, "Comparision of spacing and headway control laws for automatically controlled vehicles," Vehicle System Dynamics, vol. 23, no. 8, pp. 597-625, 1994.

[23] J. Kim, N. Kim, S. Hwang, Y. Hori, and H. Kim, "Motor control of input-split hybrid electric vehicles," International Journal of Automotive Technology, vol. 10, no. 6, pp. 733-742, 2009.

[24] K. B. Wipke, M. R. Cuddy, and S. D. Burch, "ADVISOR 2.1: a user-friendly advanced powertrain simulation using a combined backward/forward approach," IEEE Transactions on Vehicular Technology, vol. 48, no. 6, pp. 1751-1761, 1999.

[25] C.-C. Lin, H. Peng, J. W. Grizzle, and J.-M. Kang, "Power management strategy for a parallel hybrid electric truck," IEEE Transactions on Control Systems Technology, vol. 11, no. 6, pp. 839-849, 2003.

[26] M. Ehsani, Y. Gao, and A. Emadi, Modern Electric, Hybrid Electric, and Fuel Cell Vehicles: Fundamentals, Theory, and Design, CRC, Boca Raton, Fla, USA, 2nd edition, 2009.

[27] H. N. Gupta, Fundamentals of Internal Combustion Engines, Prentice-Hall, New Delhi, India, 2006.

[28] D. Rotenberg, A. Vahidi, and I. Kolmanovsky, "Ultracapacitor assisted powertrains: modeling, control, sizing, and the impact on fuel economy," IEEE Transactions on Control Systems Technology, vol. 19, no. 3, pp. 576-589, 2011.

[29] K. Ahn, S. Cho, and S. W. Cha, "Optimal operation of the power-split hybrid electric vehicle powertrain," Proceedings of the Institution of Mechanical Engineers D: Journal of Automobile Engineering, vol. 222, no. 5, pp. 789-800, 2008.
[30] M. Schulz, "Set values for a power-split hybrid electric vehicle through numerical optimization," International Journal of Alternative Propulsion, vol. 1, no. 1, pp. 6-31, 2006.

[31] K. Ahn and P. Y. Papalambros, "Engine optimal operation lines for power-split hybrid electric vehicles," Proceedings of the Institution of Mechanical Engineers D: Journal of Automobile Engineering, vol. 223, no. 9, pp. 1149-1162, 2009.

[32] D. E. Kirk, Optimal Control Theory: An Introduction, Prentice Hall, Englewood Cliffs, NJ, USA, 1970.

[33] J. M. Maciejowski, Predictive Control with Constraints, Prentice Hall, Englewood Cliffs, NJ, USA, 2002.

[34] T. Ohtsuka, "A continuation/GMRES method for fast computation of nonlinear receding horizon control," Automatica, vol. 40, no. 4, pp. 563-574, 2004.

[35] K. Muta, M. Yamazaki, and J. Tokieda, "Development of newgeneration hybrid system THS II-Drastic improvement of power performance and fuel economy," SAE Technical Paper 2004-01-0064, 2004.

[36] F. B. Li, P. Shi, L. G. Wu, and X. Zhang, "Fuzzy-model-based D-stability and non-fragile control for discrete-time descriptor systems with multiple delays," IEEE Transactions on Fuzzy Systems, 2014.

[37] L. Wu, X. Yang, and F. Li, "Nonfragile output tracking control of hypersonic air-breathing vehicles with an LPV model," IEEE/ASME Transactions on Mechatronics, vol. 18, no. 4, pp. 1280-1288, 2013.

[38] F. Li and X. Zhang, "A delay-dependent bounded real lemma for singular LPV systems with time-variant delay," International Journal of Robust and Nonlinear Control, vol. 22, no. 5, pp. 559574, 2012. 


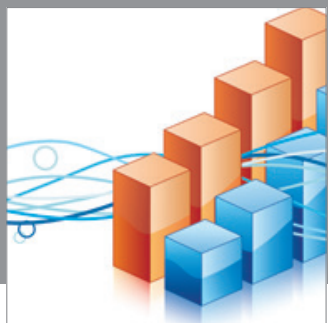

Advances in

Operations Research

mansans

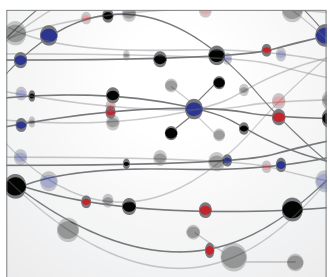

The Scientific World Journal
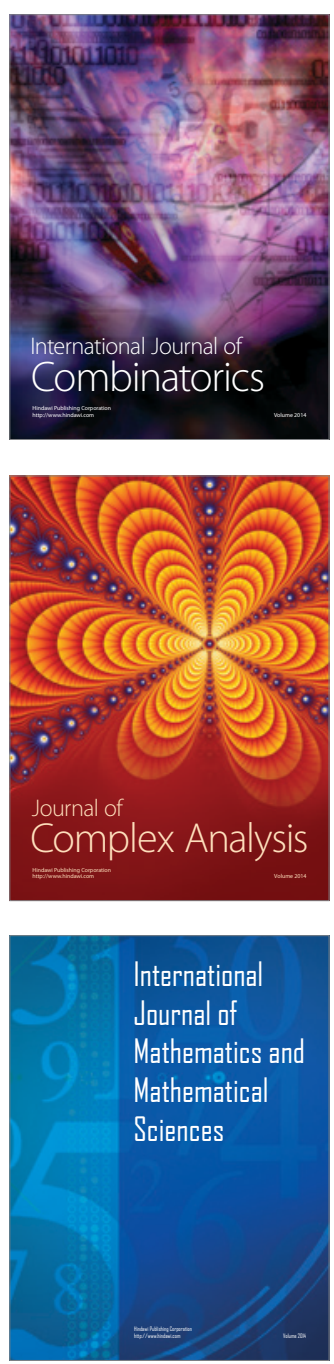
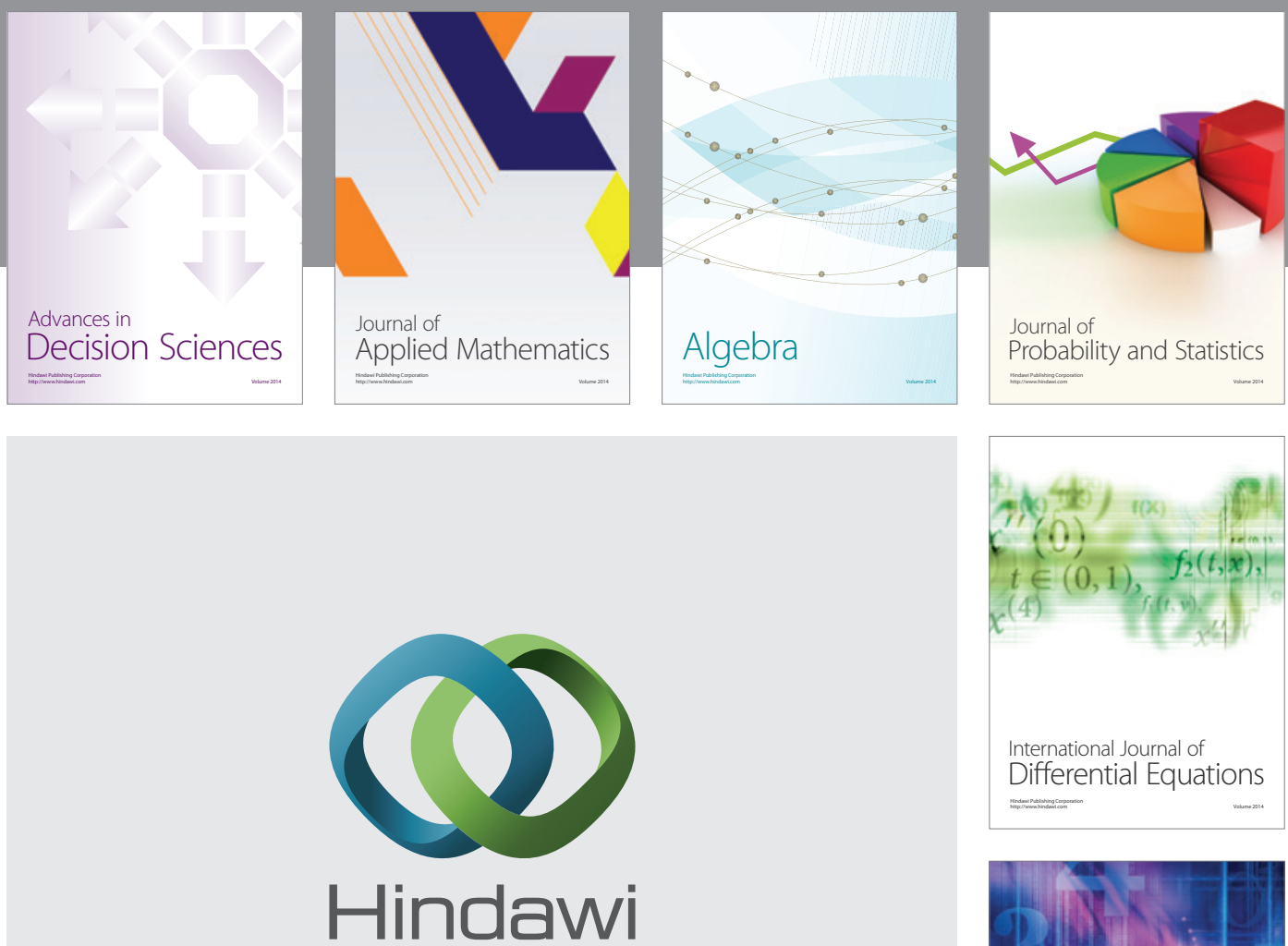

Submit your manuscripts at http://www.hindawi.com
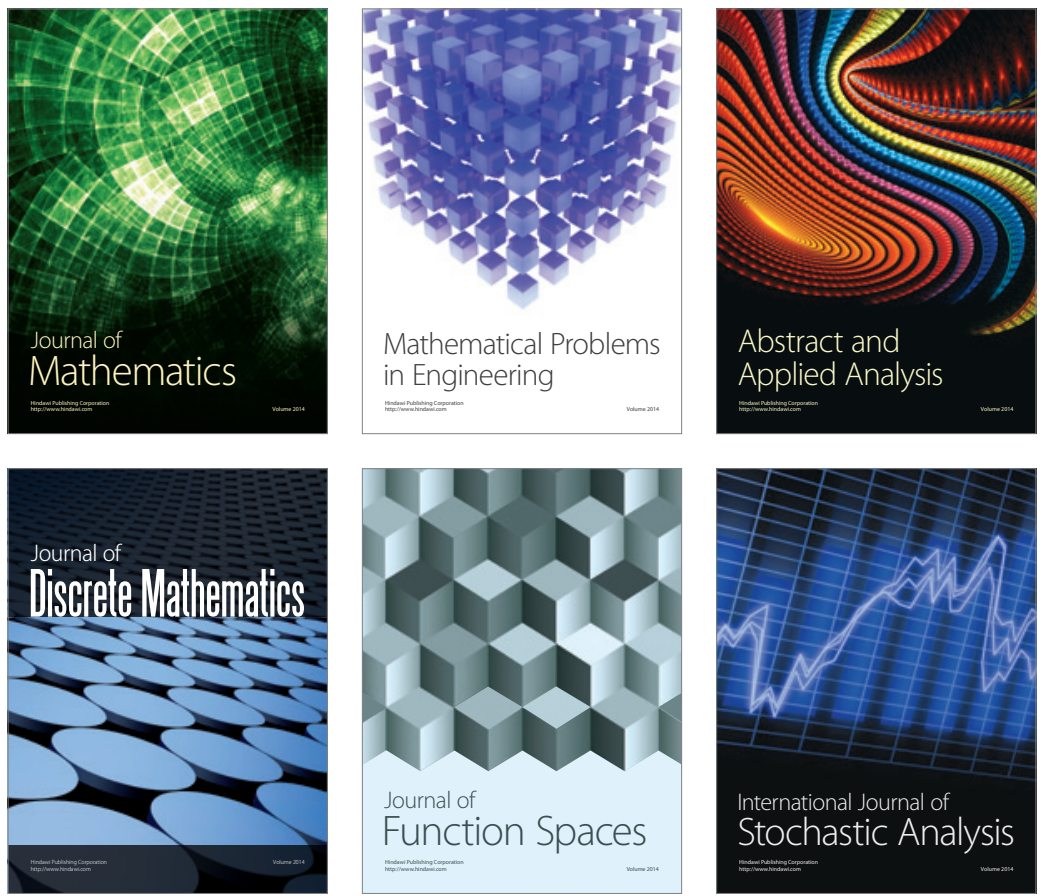

Journal of

Function Spaces

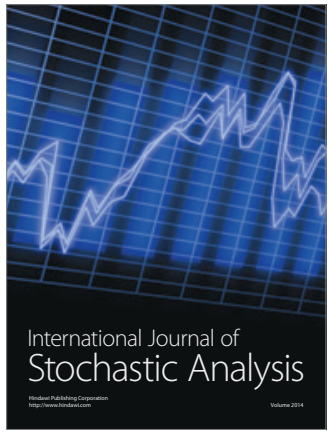

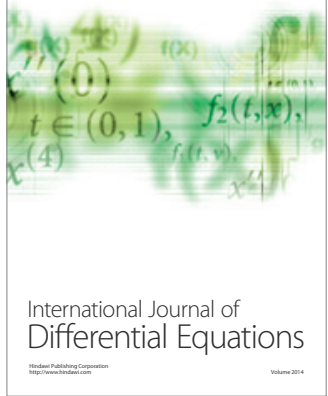
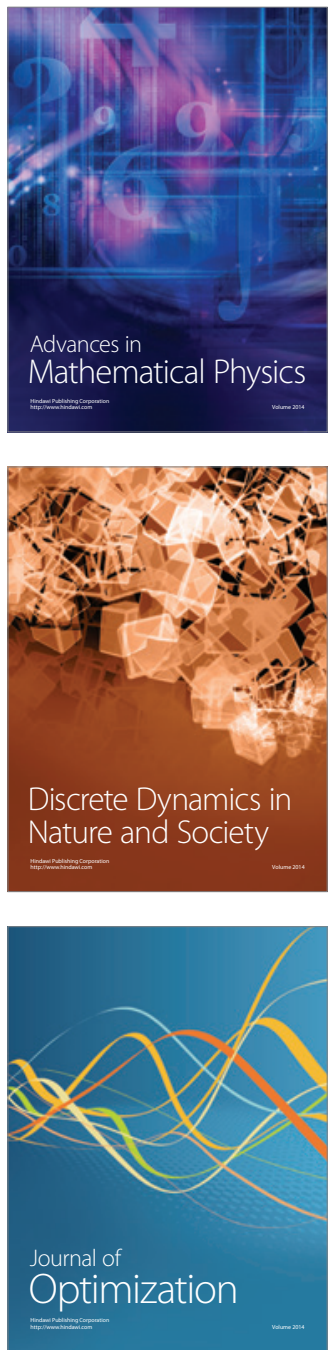